\title{
Apresentação: da educação, da arte, e das suas relações: caminhos pela história.
}

\author{
Dulce Regina Baggio Osinski * \\ Marcus Aurelio Taborda de Oliveira**
}

O objetivo deste dossiê é problematizar, a partir de um enfoque histórico, as relações entre os campos da arte e da educação. Enfatizamos não só a análise da arte como campo específico que envolve áreas profissionais distintas, a exemplo da literatura, artes visuais, música, artes cênicas (dança e teatro), jardinagem (ARGAN; 1992, p. 13), o cinema e as mídias interativas, mas também as concepções estéticas propostas para a educação geral, em diferentes tempos e lugares, por agentes plurais.

É preciso ter em mente, inicialmente, que a palavra arte pode significar coisas muito diferentes, devendo-se tentar evitar, como remarca Gombrich (1979, p. 4), a ideia da existência de uma arte com A maiúsculo e a polarização entre, por exemplo, arte erudita versus arte popular, ou arte de elite versus arte de massa.

A incursão em um campo tão vasto e de difícil delimitação, abrangendo manifestações que vão da pré-história aos nossos dias e que se espalham por todas as áreas habitadas pelo homem, exige algumas reflexões sobre sua natureza. De acordo com Argan (1992, p. 13), as funções práticas, representativas ou ornamentais a que determinadas coisas se destinam não são suficientes para a discriminação do objeto artístico. Tampouco as técnicas servem para qualificar de artísticos ou seus produtos, tendo-se em vista que "quase todas as técnicas praticadas pelo homem têm produzido por vezes obras artísticas, mas nenhuma técnica tem produzido sempre obras com valor artístico". Também a distinção entre artes maiores e menores, as primeiras relacionadas ao momento ideativo ou inventivo, e as segundas ao momento executivo ou mecânico, não se sustentariam para todas as culturas e contextos. Para os autores, o conceito de arte não define categorias e coisas, mas "um tipo de valor" ligado ao trabalho humano

* Universidade Federal do Paraná. Curitiba, Paraná, Brasil. E-mail: dulceosinski@gmail. com. https://orcid.org/0000-0002-3506-4974.

${ }^{* *}$ Universidade Federal de Minas Gerais. Belo Horizonte, Minas Gerais, Brasil. E-mail: marcustaborda@uol.com.br. https://orcid.org/0000-0002-6079-9710. 
e às suas técnicas, indicando "o resultado de uma relação entre uma atividade mental e uma atividade operacional" (ARGAN, 1992, p. 14).

Pareyson $(1989$, p. 29) chama atenção para três definições tradicionais da arte, concebida "ora como um fazer, ora como um conhecer, ora como um exprimir", concepções que coexistem, contrapondo-se umas às outras ou combinadas de formas diversas, e abrangem caracteres essenciais do fenômeno artístico. Segundo ele, o tipo de conhecimento, visão ou contemplação por ela gerado é próprio e inconfundível, qualificando de modo especial e inconfundível suas eventuais funções e revelando o sentido das coisas de modo novo e inesperado. A essas poderíamos juntar a dimensão da experiência, elemento essencial, como defendem autores tão diferentes como Dewey (2010) e Williams (1992 e 1997), para algo ser caracterizado como possuidor de estatura estética. Não se restringindo aos espaços sacralizados de museus, galerias, teatros ou salas de concerto, a experiência estética, podendo ser pensada no âmbito da realização de uma obra artística, de sua fruição ou da participação em obras de terceiros, deve ser considerada também, de acordo com Dewey, como componente das ações cotidianas:

A experiência estética é uma manifestação, um registro, uma celebração da vida de uma civilização, um meio para promover seu desenvolvimento, e também o juízo supremo sobre a qualidade dessa civilização. Isso porque, embora ela seja produzida e desfrutada por indivíduos, esses indivíduos são como são, no conteúdo de sua experiência, por causa das culturas de que participam. (DEWEY, 2010, p. 551)

As artes não são, porém, como observa Efland (1990, p. 4), reinos autônomos influenciados pelo contexto social, sendo condicionadas pelos sistemas de financiamento, controladas por mecanismos de censura e disseminadas pelos processos formativos. Assim como como elas correspondem intrinsecamente ao meio social em que são gestadas, o mesmo acontece com o sistema educacional a elas relacionado. As facilitações ou limitações impostas ao seu acesso são, por exemplo, indicadores do caráter de determinada sociedade.

Arnold Hauser (1994) e Stuart Macdonald (2004), em obras de perspectiva histórica mas com enfoques diversos, evidenciam os laços indissociáveis entre as manifestações artísticas e os respectivos projetos formativos. Seja em oficinas, academias de arte, instituições de aprendizado técnico e escolas de níveis variados, ou em ambientes informais os mais plurais, educação e arte 
têm se amalgamado com objetivos diversos, como a formação profissional do artista, a atuação docente, a educação escolar, a capacitação para o trabalho ou a formação integral pensada de modo mais abrangente.

Autores como Duarte Junior (1994) têm se debruçado sobre o potencial educacional da arte, e suas reflexões podem contribuir para uma análise mais aprofundada no âmbito da investigação histórica. Um dos pontos por ele elencados é que, "sendo a concretização dos sentimentos em formas expressivas, ela se constitui num meio de acesso a dimensões humanas não passíveis de simbolização conceitual" (p. 65), viabilizando o conhecimento das próprias experiências e sentimentos para além da linearidade da linguagem. Constituindo um meio de acesso ao mundo dos sentimentos, a arte possibilitaria seu desenvolvimento e a sua educação. A arte seria ainda um fator de agilização da imaginação, constituindo-se num estímulo permanente para a criação de "mundos possíveis" (p. 67) e novas possibilidades de ser e sentir-se. Isso permitiria, além do despertar para sentidos diferentes, a percepção da realidade social e suas limitações em relação a um estado "mais equilibrado, lúdico e estético" (p. 68). Por meio da arte seríamos ainda levados a conhecer experiências vividas por outros indivíduos ou culturas, não acessíveis ao cotidiano pessoal, o que contribuiria para a sua compreensão. Daí a necessidade de pensarmos a educação dos sentidos e das sensibilidades em chave histórica, mobilizando os diversos domínios da arte como vetores de atualização ou produção de formas de estar e ser no mundo (Taborda de Oliveira, 2012; Braghini, Munakata e Taborda de Oliveira, 2017).

Reconhecemos, especialmente no contexto brasileiro que a arte tem comparecido com regularidade, e certamente com bastante destaque, nos debates contemporâneos sobre a educação. Seja no que se refere a aludida educação dos sentidos e das sensibilidades, à cultura material da escola, aos projetos educativos de artistas-educadores, à renovação das orientações curriculares ou à formação de professores, as relações entre arte e educação têm sido cada vez mais evidenciadas para muito além das práticas escolares, configurando um amplo leque de possibilidades de estudo e intervenção educacional. Essas possibilidades abrangem tanto o ensino formal em seus diversos níveis quanto os processos de formação de professores, de profissionalização do artista e projetos artísticos de caráter informal, além de práticas que transcendem o universo escolar e afetam os processos de formação. Museus, centros culturais, escolas especializadas, instituições de ensino obrigatório, publicações diversas, assim como os diversos meios de comunicação de massa, entre outros, compõem uma rede complexa de instituições formais e informais, podem ser considerados elementos relevantes na formação tanto de artistas amadores e profissionais, 
como de um público propenso a fruir a produção artística e, quiçá, através dela se educar ou ser educado.

Os trabalhos aqui apresentados são oriundos de pesquisas que contemplam fontes de naturezas variadas, como documentos institucionais, textos literários, filmes, fotografias, jornais e revistas, impressos didáticos, obras de arte, exercícios escolares e objetos de uso didático pedagógico. Do ponto de vista das interlocuções teóricas, as interfaces exploradas por pesquisadores que se dedicam a essa problemática são igualmente múltiplas, incluindo diálogos com âmbitos tais como a história dos intelectuais, das instituições, da infância, das disciplinas, do currículo, da cultura material e da imprensa, entre outras.

Compreendemos, pois, que perscrutar os laços que ligam historicamente a educação com a arte é um desafio que merece os esforços de todos aqueles que pensam a educação em sua pluralidade temática, disciplinar e conceitual.

Entre os focos de análise previstos pelos diferentes artigos que compõem este dossiê estão as ideias e ações de intelectuais em defesa da presença da educação em arte no âmbito da formação geral; os projetos educacionais em arte nos diversos níveis escolares ou como atividades livres; a formação do artista e dos professores associados ao ensino de arte; os livros, os materiais didáticos e os métodos de ensino de arte; os debates públicos sobre a relação entre arte e educação, até a exploração da produção artística não apenas como possibilidade de fruição estética, mas como potência formativa.

O dossiê percorre uma temporalidade difusa dada a pluralidade nas várias formas de tratar a temática, além da diversidade geográfica que buscamos contemplar, publicando trabalhos de diferentes estados brasileiros, além de um trabalho sobre a Argentina e dois sobre a Itália.

Portanto, entendemos essa proposta como relevante para o campo da educação na medida em que ganham maior visibilidade, atualmente, os estudos que envolvem arte e educação no campo da pesquisa acadêmica; embora estejam crescendo progressivamente na área da história da educação nos últimos anos, ocupam ainda lugar tímido no que se refere ao percentual de artigos publicados sobre a temática em revistas bem avaliadas e fóruns especializados na área educacional.

Os trabalhos aqui apresentados compõem um mosaico que articula reflexões sobre a estética como domínio da existência, com estudos de casos empíricos sobre diferentes problemáticas que articulam a educação e a arte, o pensamento pedagógico e a produção artística, sempre indagando se e quando a arte assume uma coloração potencialmente formativa.

Por exemplo, a polissemia do termo "mimese" e suas relações com a educação são objeto de atenção de Marcus Vinicius Corrêa Carvalho. Numa abordagem de longa duração que abrange a trajetória do conceito nos últimos 
dois mil anos, Carvalho reflete sobre as questões variadas e complexas nos campos da ética e da estética a ele pertinentes, decisivas, em sua opinião, para a compreensão das dinâmicas formativas do mundo ocidental.

Considerando igualmente uma abrangência temporal extensa e também se atentando ao contexto ocidental, Glaucia Maria Costa Trinchão analisa o papel social do desenho na formação profissional da infância e adolescência na virada do século XVIII ao século XX, sua inserção no contexto escolar e sua importância na formação de mão de obra necessária à constituição de uma nova sociedade industrial que então se configurava.

Já a proposta de Eduardo Galak e María Silvia Serra consiste na análise do filme argentino intitulado "Escuela de Campeones", lançado em 1950 e dirigido por Ralph Pappier, o qual aborda as dificuldades experimentadas pelo escocês Alejandro Watson Hutton, educador que chega a Buenos Aires em 1885, para incluir a prática do futebol no currículo da escola em que atuou. Produzida em pleno governo de Juan Domingo Perón, cujos discursos enfatizavam a importância dos esportes para a Nova Argentina, a película é analisada como um produto ideológico construído a partir de uma estética peronista particular, que defendia uma proposta de educação em que os esportes eram vistos como recursos pedagógicos capazes de transmitir sentidos morais, cívicos e sociais.

Propondo-se a pensar nos aspectos da educação estética no contexto do norte da Itália, o artigo assinado por Marcus Aurelio Taborda de Oliveira observa a partir de textos publicados no semanário Il Grido Del Popolo, entre o final do século XIX e início do século XX por iniciativa dos trabalhadores tipógrafos do Piemonte, uma grande ênfase na estética como vetor da formação dos trabalhadores. De orientação socialista, o jornal propunha e divulgava, para além das atividades propriamente escolares, outras formas de educação social visando uma transformação moral e intelectual dos trabalhadores, como o teatro, a música, a literatura e as universidades populares, além de constantemente reivindicar a estética como um elemento chave para a educação dos trabalhadores em geral, sobretudo dos mais pobres.

Tendo a grande imprensa como fonte igualmente privilegiada, mas abordando contextos temporal e espacial diversos, o artigo de autoria de Dulce Regina Baggio Osinski aborda um conjunto de artigos de autoria do literato e crítico de arte José Geraldo Vieira, publicadas na Folha de São Paulo, sobre a produção artística infantil exposta na galeria de arte daquele jornal como parte das atividades do I Salão de Arte Infantil, por ele promovido. Considerando o papel daquele jornal como promotor de ações educacionais em arte, a autora tensiona as ideias do intelectual com o pensamento sobre o tema, em circulação naquele momento. 
Também abordando o pensamento crítico de um literato, expresso nesse caso em depoimentos públicos acerca de seu processo de escrita e de suas memórias, Matheus da Cruz e Zica problematiza por meio da análise da trajetória do mineiro Bartolomeu Campos de Queirós o modo como têm se constituído as relações entre arte, educação e escola em textos por ele produzidos entre as décadas de 1980 e 2000.

Por sua vez, Alexandre Fernandez Vaz oferece uma reflexão sobre uma das peças cinematográficas mais emblemáticas do período final da Guerra Fria, Asas do desejo, de Wim Wenders. O faz articulando a estética do autor com a tópica benjaminiana e reconhecendo que "a arte autêntica exprime grandes questões do tempo". Reconhecendo no filme a mão de "um diretor que tem na insuficiência, no erro e no fracasso temas recorrentes", Vaz nos lembra que história e memória são questões do presente. Logo, explora no fluxo da sua narrativa "a história coagulada em imagens expressivas". Valendo-se das imagens produzidas por Walter Benjamin, amplificadas na estética de Wenders, o autor se move como em uma cidade, articulando a sua narrativa com as de Wenders e Benjamin, fazendo da incerteza também uma possibilidade estética.

Por fim, Paolo Bianchini trata da abordagem estética em relação à arquitetura e ao mobiliário escolar no período do fascismo, na Itália. Mobilizando diferentes documentos o autor observa como a estética fascista presente na arquitetura destacava elementos concernentes ao ideário sobre o cidadão-soldado, em relação à higiene, organização, limpeza, pureza e força, tão caros àquele ideário e amplamente divulgados por artistas como Filipo Marinetti e outros, que viam no fascismo uma possibilidade de renovação política, social e cultural na qual a arte tinha um papel de destaque.

Supomos que apesar de ter a sua ênfase na história das relações entre arte e educação, o dossiê poderá interessar a todos os pesquisadores e professores preocupados com a arte em suas diversas possibilidades de afetar o campo pedagógico, na medida em que pode ajudar arrojar luz sobre debates contemporâneos tais como a redefinição curricular; a renovação da escola tanto no âmbito das políticas públicas, quanto no das suas práticas; a formação de professores; os espaços e as práticas não formais de educação, entre outros. Com essa expectativa, desejamos a todos uma boa leitura! 


\section{REFERÊNCIAS}

ARGAN, G. C. Preâmbulo ao estudo da história da arte. In: ARGAN, G. C.; FAGIOLO, M. Guia de Historia da Arte. Tradução de M. F. Gonçalves de Azevedo. Lisboa: Editorial Estampa, 1992.

BRAGHINI, K.; MUNAKATA, K.; TABORDA DE OLIVEIRA, M. A. Diálogos sobre a história da educação dos sentidos e das sensibilidades. Curitiba: Editora UFPR, 2017.

DEWEY, J. Arte como experiência. Tradução de Vera Ribeiro. São Paulo: Martins Fontes, 2010.

DUARTE JUNIOR, J. F. Por que arte-educação? Campinas: Papirus, 1994.

EFLAND, A. A history of art-education: intellectual and social currents in teaching of the visual arts. New York: Teachers College Press, 1990.

GOMBRICH, E. H. A história da arte. Tradução de Álvaro Cabral. Rio de Janeiro: Zahar Editores, 1979.

HAUSER, A. História social da literatura e da arte. Tradução de Álvaro Cabral. São Paulo: Martins Fontes, 1994.

MACDONALD, Stuart. The history and philosophy of art education. Cambridge: The Lutterworth Press, 2004.

PAREYSON, L. Os problemas da estética. Tradução de Maria Helena Nery Garcez. São Paulo: Martins Fontes, 1989.

TABORDA DE OLIVEIRA, M. A. Sentidos e sensibilidades: sua educação na história. Curitiba: Editora UFPR, 2012.

WILliANS, R. Cultura. Rio de Janeiro: Paz e Terra, 1992.

La política del modernismo: contra los nuevos conformistas. Buenos Aires: Manantial, 1997. 